\title{
Electrochemical Corrosion Behavior of Carbon Steel Reinforcement in Concrete Containing Limestone and Mesoporous Silica Nanoparticles under Acidic Environment
}

\author{
Qi Zhang
}

Weifang University of Science and Technology, Shouguang 262700, China

E-mail: aqi1203@ sina.com and wkjzzhangq@wfust.edu.cn

doi; 1020964/2020.12.16

Received: 5 August 2020 / Accepted: 17 September 2020 / Published: 31 October 2020

In this study, corrosion behavior of carbon steel rebar embedded in concrete structures containing Limestone and mesoporous silica nanoparticles (MSNs) as partial replacement materials of Portland cement (PC) in 5\% sulfuric acid solution were investigated. Polarization analysis, electrochemical impedance spectroscopy (EIS) measurement, water absorption test and mass loss evaluation were utilized to investigate the corrosion resistance of carbon steel rebars. The concrete sample containing both limestone and MSNs admixtures (10M10L) indicated a lower value of mass loss for carbon steel rebar than the other samples which caused superior corrosion behavior of steel reinforced concrete. The 10M10L concrete sample shows a considerable reduction in water absorption. The passive current density in the 10M10L sample was lower compared to the other samples, indicating the enhanced corrosion resistance of carbon steel reinforced concrete containing both MSNs and limestone admixtures. The EIS result reveals that the 10M10L sample indicates a significant improvement in polarization resistance value showing a higher corrosion resistance compared to the other samples.

Keywords: Electrochemical corrosion; Carbon steel rebar; Limestone; Mesoporous silica Nanoparticles; Sulfuric acid solution; Admixture effect

\section{$\underline{\text { FULL TEXT }}$}

(C) 2020 The Authors. Published by ESG (www.electrochemsci.org). This article is an open access article distributed under the terms and conditions of the Creative Commons Attribution license (http://creativecommons.org/licenses/by/4.0/). 